\title{
Influences on the pharmacokinetics of oxycodone: a multicentre cross-sectional study in 439 adult cancer patients
}

\author{
Trine Naalsund Andreassen • Pål Klepstad • \\ Andrew Davies • Kristin Bjordal • Staffan Lundström • \\ Stein Kaasa • Ola Dale
}

Received: 24 February 2010 /Accepted: 27 October 2010/Published online: 8 December 2010

(C) The Author(s) 2010. This article is published with open access at Springerlink.com

\begin{abstract}
Objective Oxycodone is widely used for the treatment of cancer pain, but little is known of its pharmacokinetics in cancer pain patients. The aim of this study was to explore the relationships between ordinary patient characteristics and serum concentrations of oxycodone and the ratios noroxycodone or oxymorphone/oxycodone in cancer patients.
\end{abstract}

T. N. Andreassen · P. Klepstad · O. Dale

Pain and Palliation Research Group,

Department of Circulation and Medical Imaging,

Faculty of Medicine,

Norwegian University of Science and Technology,

Trondheim, Norway

T. N. Andreassen

e-mail: trine.n.andreassen@ntnu.no

P. Klepstad

e-mail: pal.klepstad@ntnu.no

S. Kaasa

Pain and Palliation Research Group,

Department of Cancer Research and Molecular Medicine,

Faculty of Medicine,

Norwegian University of Science and Technology,

Trondheim, Norway

e-mail: Stein.Kaasa@ntnu.no

\section{S. Kaasa}

Palliative Medicine, Department of Oncology,

St. Olav's University Hospital,

Trondheim, Norway

\section{A. Davies}

Department of Palliative Medicine,

The Royal Marsden NHS Foundation Trust,

Sutton, UK

e-mail: andrew.davies@rmh.nhs.uk
Methods Four hundred and thirty-nine patients using oral oxycodone for cancer pain were included. The patients' characteristics (sex, age, body mass index [BMI], Karnofsky performance status, "time since starting opioids", "oxycodone total daily dose", "time from last oxycodone dose", use of CYP3A4 inducer/inhibitor, "use of systemic steroids", "number of medications taken in the last $24 \mathrm{~h}$ ", glomerular filtration rate (GFR) and albumin serum concentrations) influence on

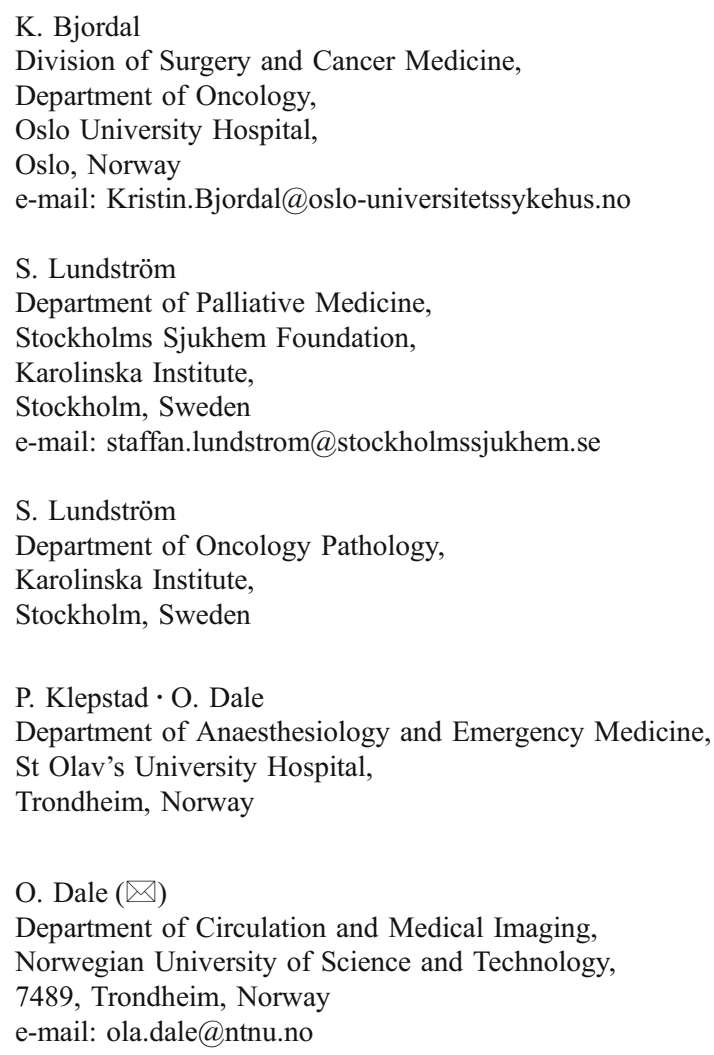


oxycodone serum concentrations or metabolite/oxycodone ratios were explored by multiple regression analyses.

Results Sex, CYP3A4 inducers/inhibitors, total daily dose, and "time from last oxycodone dose" predicted oxycodone concentrations. CYP3A4 inducers, total daily dose, and "number of medications taken in the last $24 \mathrm{~h}$ " predicted the oxymorphone/oxycodone ratio. Total daily dose, "time from last dose to blood sample", albumin, sex, CYP3A4 inducers/inhibitors, steroids, BMI and GFR predicted the noroxycodone/oxycodone ratio.

Conclusion Women had lower oxycodone serum concentrations than men. CYP3A4 inducers/inhibitors should be used with caution as these are predicted to have a significant impact on oxycodone pharmacokinetics. Other characteristics explained only minor parts of the variability of the outcomes.

Keywords Oxycodone $\cdot$ Metabolites · Ratios · Cancer population · Drug-drug interactions $\cdot$ Serum concentrations

\section{Introduction}

Twenty to forty-five percent of patients with advanced cancer suffer from moderate to severe pain that requires treatment with opioids [1-3]. Oxycodone and morphine are two of the frequently used opioids in cancer pain treatment. Pharmacokinetic aspects of morphine and metabolites have been extensively studied and it has been shown that there are large inter-individual differences in serum concentrations of morphine and metabolites, even after dose correction [4]. Serum concentrations of morphine and metabolites are related to morphine dose and route of administration $[4,5]$. While renal function has no influence on the serum concentrations of morphine, the levels of metabolites increase with decreasing renal function [5].

The clinical efficacy of oral oxycodone is similar to that of morphine, but oxycodone is more potent with an equianalgesic ratio of $1 / 1.5-2[6,7]$. This may partly be explained by the fact that the oral bioavailability of oxycodone ranges from $60-87 \%[8,9]$, which is higher than the $20-40 \%$ for morphine [10-12]. Clinical pharmacokinetic studies on oxycodone and its major metabolites in patients are scarce [13-16], especially for cancer pain patients. Oxycodone is extensively metabolised in the liver, mainly via CYP3A4 to the inactive metabolite noroxycodone ( $47 \%$ of the dose), by 6-keto reduction to the most likely inactive metabolites, $\alpha$ - and $\beta$-oxycodol ( $8 \%$ of the dose), and via CYP2D6 to the active metabolite oxymorphone ( $11 \%$ of the dose), which is mainly found in a conjugated form in plasma. A third, possibly active metabolite, noroxymorphone, is formed from noroxycodone via CYP2D6, but also to a lesser degree from oxymorphone via CYP3A4 (Fig. 1) [17].

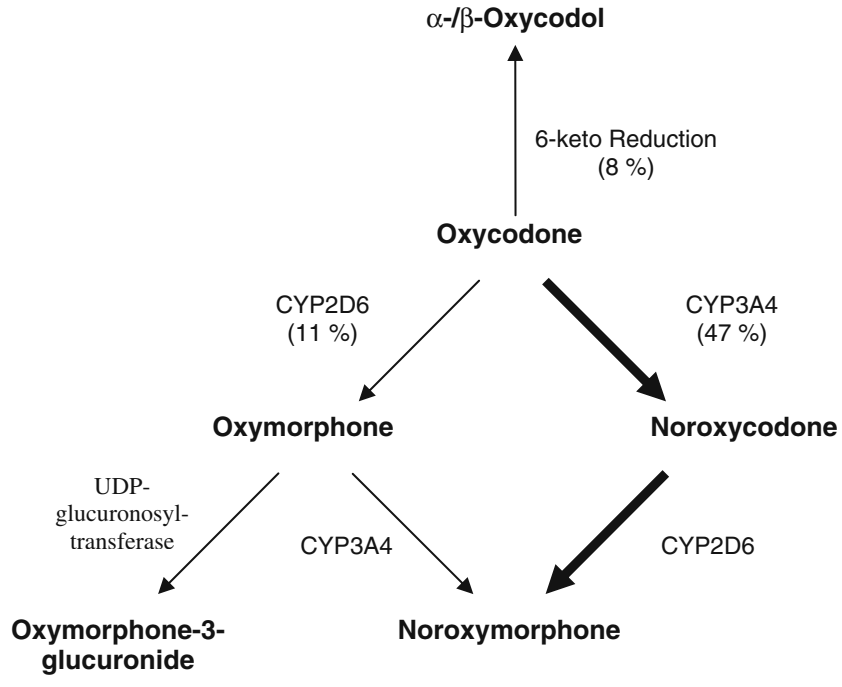

Fig. 1 Oxycodone metabolism. The major metabolic pathway (bold arrows) of oxycodone is the formation of noroxycodone via CYP3A4 enzymes. Noroxycodone is further metabolised to noroxymorphone via CYP2D6 enzymes. The minor metabolic pathways (narrow arrows) are formation of oxymorphone via CYP2D6 enzymes, and 6-keto reduction to $\alpha$ - and $\beta$-oxycodol. Oxymorphone is further metabolised to noroxymorphone via CYP3A4 enzymes

CYP3A4 is involved in the metabolism of about $50 \%$ of all drugs, and does not seem to be under polymorphic regulation $[18,19]$. Inhibition and induction of CYP3A4 is clinically important as it can cause drug interactions [20, 21]. CYP3A4 activity is subject to a sex difference as higher activity is reported in women than in men [22, 23]. Furthermore, a 50-fold inter-individual difference in CYP3A4 expression has been reported [24], and diseases such as cancer can down-regulate the expression $[25,26]$.

CYP2D6 is polymorphically regulated and expressed in four different phenotypes [27, 28]. CYP2D6 is not inducible, but it may be inhibited by several drugs [29-31]. Thus, an individual's phenotype can change (phenocopying) with co-administration of CYP2D6 inhibitory drugs [32, 33]. A recent study by Samer et al. [34] has shown that oxycodone and noroxycodone $\mathrm{AUC}_{\alpha}$ increased, and oxymorphone AUC decreased, after blocking the CYP2D6 metabolic pathways of oxycodone with quinidine in healthy volunteers. Samer et al. also found decreased noroxycodone $\mathrm{C}_{\max }$ and increased oxymorphone $\mathrm{AUC}_{\alpha}$ after blocking the CYP3A4 metabolic pathway with ketoconazole. Thus, oxycodone seems to be vulnerable to drug-drug interactions.

Moreover, Samer's study indicated that oxymorphone, despite its modest levels in serum, may contribute to oxycodone analgesia in humans.

The metabolites of oxycodone are excreted through the kidneys in free or conjugated form $[9,35]$. Peak plasma concentrations of oxycodone and noroxycodone are higher in patients with mild-to-moderate hepatic dysfunction or mild-to-severe renal dysfunction, and oxymorphone con- 
centrations are lower in patients with impaired hepatic function [36-38]. Elderly patients may have higher plasma concentrations of oxycodone than younger patients [39]. BMI (body mass index) is also potentially important to drug disposition and metabolism. Several studies have described pharmacokinetic differences for drugs in obese compared from non-obese subjects [40]. However, insufficient data for morphine on this topic [41], and no such data on oxycodone, exist.

The present study is part of the European Pharmacogenetic Opioid Study (EPOS). Of the 2,294 cancer patients included in EPOS, 442 used oral oxycodone for their cancer pain. The primary aim was to examine factors that may affect the pharmacokinetics of oxycodone. The secondary aim was to explore factors that influence the most important metabolic ratios, noroxycodone/oxycodone and oxymorphone/oxycodone. Based on the above considerations, it was expected that the serum concentrations of oxycodone was influenced by dose, time since last dose to blood sample, sex, age and BMI; the ratios noroxycodone or oxymorphone to oxycodone by age, CYP3A4 inhibitors or inducers, or CYP2D6 inhibitors, number of co-medications and GFR, and the former also by sex. Moreover, a large inter-individual variability in serum concentrations and ratios was expected.

\section{Materials and methods}

\section{Ethics}

This multicentre study was performed according to the guidelines of the Helsinki declaration and was approved by the relevant Research Ethics Committee of each study centre. Before entering the study, participating patients gave written informed consent.

\section{Subjects}

Patients included in EPOS were aged 18 years or more, had a verified malignant disease, and were treated with regular oral, subcutaneous, transdermal or intravenous opioids (morphine, methadone, fentanyl, hydromorphone, buprenorphine, ketobemidone or oxycodone) for their cancer pain for a minimum duration of 3 days. Exclusion criteria were patients who were not capable of speaking the language used at the study centre. Patients treated with oral oxycodone were eligible for the present study.

Assessments and recordings

At the time of inclusion age, sex, weight, height, ethnicity and cancer diagnosis were registered. The patients' functional status was assessed by the Karnofsky performance status [42]. All medications and dosages including opioids for the previous $24 \mathrm{~h}$, duration of opioid treatment, use of rescue opioids in last $24 \mathrm{~h}$, route of opioid administration, and the time interval between last opioid administration and blood sampling (see below) were recorded. Medications were categorised as to whether they were CYP3A4 inducers or inhibitors, or a CYP2D6 inhibitor. The published tables differ significantly $[18,43]$. The web-based table of Flockhart, for instance, lists glucocorticoids as CYP3A4 inducers, while this group of drugs is not listed by Wilkinson. However, the most recent and extensive list was used for this classification. Moreover, steroids and the other CYP3A4 inducers were categorised as two separate variables. Body mass index (BMI) was calculated using the international system of units, BMI $=$ weight $(\mathrm{kg}) /$ height $^{2}\left(\mathrm{~m}^{2}\right)$. Renal function was expressed as calculated glomerular filtration rate (GFR)/1.73 $\mathrm{m}^{2}$ body surface [44, 45]. Albumin serum concentrations were measured using standard analytical methods.

Blood samples were obtained shortly before drug administration of the patients' scheduled oral opioid medication (trough value). For practical reasons blood samples from out-patients $(n=68)$ were taken at the time of examination. Blood samples for opioid analyses in serum were collected in tubes with no additives and left at ambient temperatures for 30-60 min before centrifugation at $2,500 \times \mathrm{g}$ (approximately 3,000 $\mathrm{rpm}$ ) for $10 \mathrm{~min}$. Serum was then aliquoted and stored at $-80^{\circ} \mathrm{C}$ prior to analysis.

\section{Statistics}

A pre-study formal sample size calculation was not performed since this was an explorative subgroup study within the larger EPOS study. However, the sample size is larger than Green's recommendations $(104+k$ independent variables) [46], and large enough to detect a medium effect according to Miles and Shevlin [47].

Descriptive group data are given as median (minimum to maximum) values. Median oxycodone and metabolites' serum concentrations and ratios were calculated from the hospitalised patients (336 slow release, 35 immediate release) independent of time since last scheduled dose to blood sample and opioid used as rescue medication. Spearman rank correlations were used to explore the association between patient demographic variables and serum concentrations. To protect against the risk for type I error due to multiple testing, only variables with $p$ values less than 0.01 were considered statistically significant, and intended to be included into the multiple regression analyses. However, variables which did not meet the $p<0.01$ criteria, but had shown to be statistically significant in a similar study on morphine [4] (age), or were important for determining the progress of cancer in the individual subject (Karnofsky performance status) were also included into the multiple regression analyses. 
Serum concentrations of oxycodone, metabolites and ratios of oxymorphone/oxycodone and noroxycodone/oxycodone were $\log _{10}$-transformed to yield normally distributed residuals. The effect of patient variables on $\log _{10}$-transformed serum concentrations of oxycodone and oxymorphone/oxycodone and noroxycodone/oxycodone ratios were explored by backward stepwise linear regressions, with the criterion for removal of a variable of $p>0.1$. Because data covering all variables for all the patients were not available (as seen in Table 4 with the different $n$ for the three regression analyses), the backward stepwise linear regressions were done manually. $p$ values $\leq 0.05$ (two-sided) were considered statistically significant in the final model. Variables included in the multiple regression analyses were sex, BMI, "time since starting opioids", "time since last oxycodone (scheduled or rescue) dose before blood sample", "number of medications taken in last $24 \mathrm{~h}$ ", "oxycodone total (scheduled and rescue) daily dose", "use of CYP3A4 inducer", "use of CYP3A4 inhibitor", systemic steroids, glomerular filtration rate (GFR), albumin serum concentrations (all $p<0.01$ ), age and Karnofsky status. "Time since starting opioid" was calculated from the time the patient started with any of the opioids fentanyl, morphine, oxycodone, methadone, buprenorphine, ketobemidone or hydromorphone. Mann-Whitney $U$ test was used to compare oxycodone total daily dose between men and women, and to compare serum concentrations of oxycodone, oxymorphone, and the oxymorphone/oxycodone ratio between users and non-users of CYP2D6 inhibitors. $p$ values $\leq 0.05$ (two-sided) were considered statistically significant in the MannWhitney $U$ tests. The statistical software SPSS for Windows v. 16.0 was used for all statistical analyses.

\section{Materials}

\section{Chemicals and reagents}

Oxycodone, oxycodone- $\mathrm{d}_{6}$, noroxycodone- $\mathrm{HCl}$, noroxycodone- $\mathrm{d}_{3} \mathrm{HCl}$, oxymorphone, oxymorphone- $\mathrm{d}_{3}$ and noroxymorphone $\mathrm{HCl}$ were obtained from Cerillant (Round Rock, TX, USA). Acetonitrile (HPLC grade) was obtained from LabScan and de-ionised water $>18 \Omega$ from Purelab Ultra (ELGA, Bergman, Norway). Formic acid (analytical grade) was obtained from SDS (Ratstatt, Germany). Plasma for standard curve calibrations and quality controls was obtained from St. Olav's Hospital blood donor centre (Trondheim, Norway).

\section{Instrumentation and equipment}

The liquid chromatography system used was an Agilent 1100 series HPLC system fitted with a G1311A quaternary pump, a G1322A degasser and a G1313A autosampler, all from Agilent Technologies (Matriks, Norway). Column heating was performed with a Universal-Thermostat column oven from Mikrolab (Aarhus, Denmark). The Zorbax SBC18 $(2.1 \times 150 \mathrm{~mm}, 5 \mu \mathrm{m})$ column and the Zorbax SB-C8 pre-column $(4.6 \times 12.5 \mathrm{~mm}, 5 \mu \mathrm{m})$ were purchased from Agilent Technologies. The MS-MS system consisted of an API 4000 QTrap and API 5000 triple quadruple mass spectrometer from Sciex Instruments (Applied Biosystems, Streetville, ON, Canada).

\section{Serum concentrations}

Edwards and Smith's [48] protein precipitation method, with the following modifications, was applied to extract oxycodone and its metabolites oxycodone, noroxycodone, oxymorphone and noroxymorphone from $0.2 \mathrm{ml}$ serum. After addition of internal standards (oxycodone- $\mathrm{d}_{6}$, noroxycodone- $\mathrm{d}_{3}$ and oxymorphone- $\mathrm{d}_{3}, 20 \mu \mathrm{l}$ of a $50 \mathrm{ng} /$ $\mathrm{ml}$ solution) to the sample, proteins were precipitated by adding acetonitrile $(0.9 \mathrm{ml})$. The sample was then whirlmixed and left in the fridge for 30-60 min. The sample was centrifuged at $12,000 \times \mathrm{g}$ for $10 \mathrm{~min}$, supernatant was then frozen at $-80^{\circ} \mathrm{C}$ and evaporated in a vacuum concentrator (MAXI dry lyo, Heto Holten A/S, Allerø, Denmark) until freeze dried $(2-3 \mathrm{~h})$. A solution of $50 \mu \mathrm{l}$ containing $20 \%$ acetonitrile with $0.1 \%$ formic acid and $80 \%$ water with $1.0 \%$ formic acid was added, the sample whirlmixed and centrifuged at $12,000 \times \mathrm{g}$ for $10 \mathrm{~min}$. The supernatant was transferred into LCMS vial and capped. Oxymorphone- $\mathrm{d}_{3}$ was used as an internal standard for noroxymorphone.

An LC-MS/MS method validated in accordance with Dadgar [49] and Shah [50] was used for identification and quantitative analysis of drug and metabolites in the extracted samples. Analytical separation was performed with a column oven at $40^{\circ} \mathrm{C}$ using a Zorbax SB-C18 column with a Zorbax SB-C8 pre-column at a flow rate of $0.2 \mathrm{ml} / \mathrm{min}$ and a gradient elution. The gradient was initiated with $20 \%$ acetonitrile with $0.1 \%$ formic acid and $80 \%$ water with $1.0 \%$ formic acid $(5.0 \mathrm{~min})$, and then with a stepwise increase to $100 \%(5.20 \mathrm{~min})$ acetonitrile with $0.1 \%$ formic acid. After $7.0 \mathrm{~min}$ the acetonitrile concentration was decreased to $20 \%$ (7.2 $\mathrm{min})$ and was kept constant until end of the run (14.0 min). Injection volume was $10 \mu 1$. The MS/MS system was operated with multiple ion monitoring (MRM), with the following ions monitored: $316.1 \rightarrow$ 241.1 for oxycodone, $302.1 \rightarrow 227.2$ for noroxycodone and oxymorphone, and $288.0 \rightarrow 213.0$ for noroxymorphone.

The standard curve ranges were oxycodone $0.32-16 \mathrm{nM}$ $(0.1-500 \mathrm{ng} / \mathrm{ml})$, oxymorphone $0.07-166 \mathrm{nM}(0.02-50 \mathrm{ng} / \mathrm{ml})$, noroxycodone $0.17-3,314 \mathrm{nM}(0.05-1,000 \mathrm{ng} / \mathrm{ml})$ and noroxymorphone $0.17-696 \mathrm{nM}(0.05-200 \mathrm{ng} / \mathrm{ml})$. The calibration curves were obtained from linear or quadratic regression with $1 / \mathrm{x}$ or $1 / \mathrm{x}^{2}$ weighing of the analyte-to- 
internal-standard ratios of peak area versus the respective analyte concentration. Correlation coefficients were $r>0.998$ for all standard curves. Coefficients of variation (intra- and inter-day) for each analyte were 16.5 and $8.3 \%(0.32 \mathrm{nM}), 4.4$ and $4.0 \%(1.6 \mathrm{nM}), 6.0$ and $3.9 \%(31.7 \mathrm{nM}), 4.5$ and $3.7 \%$ $(634.2 \mathrm{nM})$, and 5.5 and $4.8 \%(1,268.4 \mathrm{nM})$ for oxycodone; 8.8 and $6.7 \%(0.8 \mathrm{nM}), 5.8$ and $3.4 \%(3.6 \mathrm{nM}), 4.4$ and $3.9 \%$ $(76.2 \mathrm{nM}), 10.8$ and $5.6 \%(1,325.6 \mathrm{nM})$, and 6.5 and $5.8 \%$ $(2,651.2 \mathrm{nM})$ for noroxycodone; 10.0 and $7.5 \%(0.2 \mathrm{nM}), 9.7$ and $7.1 \%(0.3 \mathrm{nM}), 8.9$ and $4.4 \%(3.3 \mathrm{nM}), 6.0$ and $3.6 \%$ $(66.4 \mathrm{nM})$, and 7.0 and $3.8 \%(132.7 \mathrm{nM})$ for oxymorphone; and 10.0 and $7.1 \%(0.7 \mathrm{nM}), 9.2$ and $5.7 \%(0.9 \mathrm{nM}), 6.9$ and $6.5(12.2 \mathrm{nM}), 6.4$ and $5.5 \%(208.8 \mathrm{nM})$, and 14.8 and $7.7 \%(471.7 \mathrm{nM})$ for noroxymorphone. The limits of quantification were $0.32 \mathrm{nM}(0.1 \mathrm{ng} / \mathrm{ml})$ for oxycodone, $0.07 \mathrm{nM}(0.02 \mathrm{ng} / \mathrm{ml})$ for oxymorphone, and $0.17 \mathrm{nM}$ $(0.05 \mathrm{ng} / \mathrm{ml})$ for noroxycodone and noroxymorphone.

\section{Results}

\section{Patients}

The EPOS included 2,294 cancer patients from 17 centres in 11 European countries, with 461 patients ( $98 \%$ Caucasians) treated with oxycodone. Twenty-two patients were excluded; 17 because they were treated with intravenous (5) or subcutaneous (12), oxycodone, 2 because of lack of a blood sample and 3 because neither oxycodone nor metabolites could be detected in serum. Thus, 439 patients using oral oxycodone (394 slow release, 48 immediate release) were included for analysis (Fig. 2).

The patients' demographic data are shown in Table 1. Their median age was 63 years, and $56 \%$ were men. Median Karnofsky performance score was 70\%. Two-thirds had lung, breast, prostate or GI cancer. Eighty-two percent of the patients had metastases. Thirteen percent $(n=59)$ of the participants were suffering from renal disease/dysfunction (GFR $<60 \mathrm{ml} / \mathrm{min}$ per $1.73 \mathrm{~m}^{2}$ body surface), while $58 \%(n=253)$ had albumin serum concentrations below the normal range $(35-55 \mathrm{~g} / \mathrm{L})$. Forty-four percent of the patients used rescue opioid doses ( $90 \%$ used oxycodone). One-hundred and sixty-nine patients used oral immediate release, 6 subcutaneous and 1 intravenous oxycodone as rescue medication. Nineteen patients used opioids other than oxycodone as rescue medication.

Median time from last opioid dose to blood sample was $10(0.1-17) \mathrm{h}$.

Virtually all patients (99\%) used other drugs in addition to opioids, and 12 used herbal medications. Patients had taken a median of 6 non-opioid drugs during the previous $24 \mathrm{~h}$. The most frequently co-administered classes of drugs were laxatives $(57 \%)$, histamine 2 receptor antagonists

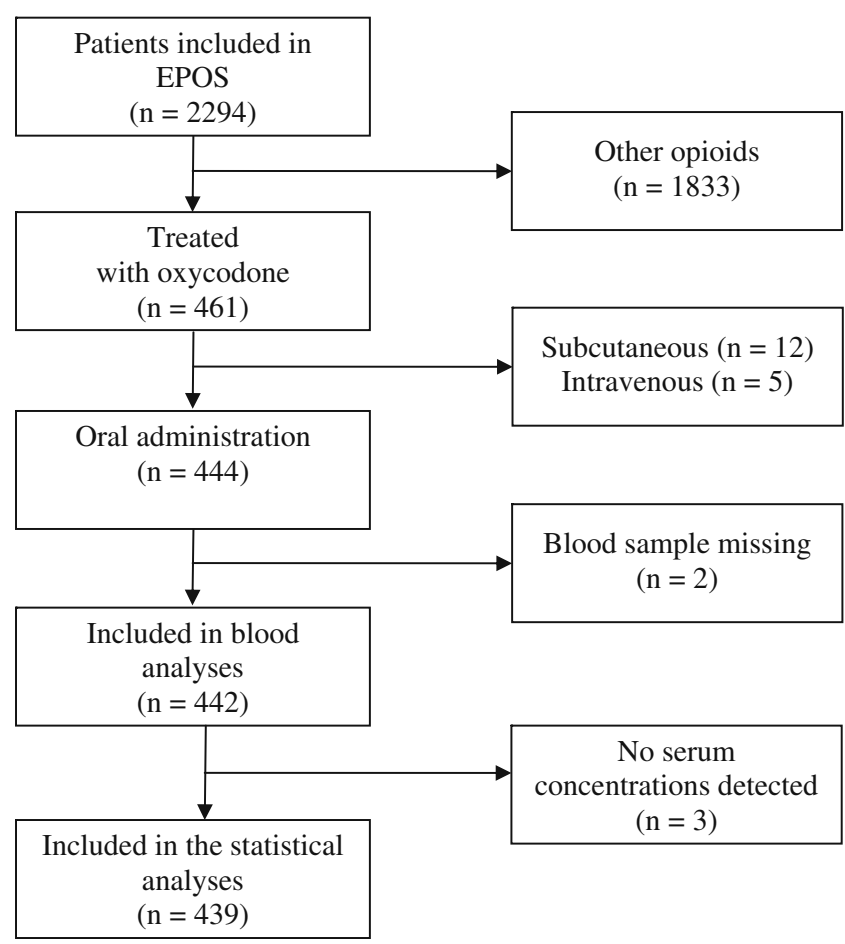

Fig. 2 Study flow sheet. The European Pharmacogenetic Opioid Study included 2,294 cancer patients of whom 461 were treated with oxycodone. Four hundred and forty-four used oral oxycodone, 439 were included in the analyses

(57\%), paracetamol (53\%), systemic steroids $(48 \%)$ and antiemetics (37\%). Thirty-five patients used one or more medications known to inhibit CYP2D6 such as haloperidol (28), fluoxetine (2) or paroxetine (1), hydroxyzine (2), doxepine (1), chlorpromazine (1) and amidarone (1). Fifteen used the CYP3A4 inhibitor fluconazole. Other CYP3A4 inhibitors used were clarithromycin (2), verapamil (3), nelfinavir (1), itraconazole (1) and diltiazem (1). Three patients used the CYP3A4 inducer carbamazepine and one used phenobarbital $[18,43]$. Two-hundred and twelve used systemic steroids that according to Flockhart [43] are CYP3A4 inducers.

The median oxycodone scheduled daily dose was 60 (range 10-760) $\mathrm{mg}$. The median oxycodone rescue dose was 20 (range 5-360) $\mathrm{mg}$, and median oxycodone total daily dose (sum of scheduled and rescue) was 80 (range 10-960) $\mathrm{mg}$. The 95\% CIs for the mean oxycodone scheduled daily dose were $87-109 \mathrm{mg} / 24 \mathrm{~h}, 29-42 \mathrm{mg} /$ $24 \mathrm{~h}$ for rescue and $102-128 \mathrm{mg} / 24 \mathrm{~h}$ total daily dose (Table 2). The resulting serum concentrations of oxycodone and metabolites and their ratios displayed wide ranges, even after dose correction (Table 3). Oxycodone serum concentration varied from 0 to 1,890 (median 100) $\mathrm{nM}$, while those of noroxycodone, oxymorphone and noroxymorphone varied from 0 to 4,858 (median 106), 0-27 (median 1.5 ) and 0-509 (median 17) nM respectively. The 95\% CIs for the uncorrected mean values were $139-183 \mathrm{nM}$ for 
Table 1 Demographics and characteristics of the 439 patients included in the analyses

\begin{tabular}{|c|c|}
\hline Demographic/characteristic & Statistic \\
\hline Men/women & $247 / 192^{\mathrm{a}}$ \\
\hline Age (years) & $63(18-91)^{\mathrm{b}}$ \\
\hline BMI $\left(\mathrm{kg} / \mathrm{m}^{2}\right)$ & $24(14-41)^{\mathrm{b}}$ \\
\hline Height $(\mathrm{cm})$ & $171(148-199)^{\mathrm{b}}$ \\
\hline Karnofsky performance status score (\%) & $70(20-90)^{\mathrm{b}}$ \\
\hline Time since cancer diagnosis (months) & $18(0-286)^{\mathrm{b}}$ \\
\hline Time since start opioids (months) & $1(0-97)^{\mathrm{b}}$ \\
\hline $\begin{array}{l}\text { Time since last oxycodone dose before } \\
\text { blood sample (hours) }\end{array}$ & $10(0.1-17)^{\mathrm{b}}$ \\
\hline $\begin{array}{l}\text { Number of medications in addition to } \\
\text { oxycodone }\end{array}$ & $6(0-17)^{\mathrm{b}}$ \\
\hline $\begin{array}{l}\text { Glomerular filtration rate (GFR) } \\
\left(\mathrm{ml} / \mathrm{min} / 1.73 \mathrm{~m}^{2}\right)\end{array}$ & $96(24-261)^{\mathrm{b}}$ \\
\hline Serum albumin $(g / L)$ & $33(10-91)^{\mathrm{b}}$ \\
\hline Oxycodone rescue medication (yes/no) & $176 / 263^{\mathrm{a}}$ \\
\hline Oral immediate release oxycodone & $169^{\mathrm{a}}$ \\
\hline Subcutanous oxycodone & $6^{\mathrm{a}}$ \\
\hline Intravenous oxycodone & $1^{\mathrm{a}}$ \\
\hline Other than oxycodone & $19^{\mathrm{a}}$ \\
\hline \multicolumn{2}{|l|}{ Cancer diagnosis } \\
\hline Gastrointestinal (inclusive pancreas, liver) & $19.8^{\mathrm{c}}$ \\
\hline Prostate & $17.5^{\mathrm{c}}$ \\
\hline Lung (inclusive mesothelioma) & $16.6^{\mathrm{c}}$ \\
\hline Breast & $14.8^{\mathrm{c}}$ \\
\hline Female reproductive organs & $7.5^{\mathrm{c}}$ \\
\hline Haematological & $6.6^{\mathrm{c}}$ \\
\hline Other urological & $6.4^{\mathrm{c}}$ \\
\hline Head and neck & $2.5^{\mathrm{c}}$ \\
\hline Skin & $2.1^{\mathrm{c}}$ \\
\hline Sarcoma & $2.0^{\mathrm{c}}$ \\
\hline Other cancer diagnoses & $5.7^{\mathrm{c}}$ \\
\hline More than one diagnosis & $4.3^{\mathrm{c}}$ \\
\hline Unknown origin & $2.7^{\mathrm{c}}$ \\
\hline Metastases (yes/no) & $359 / 55^{\mathrm{a}}$ \\
\hline Bone & $49.8^{\mathrm{c}}$ \\
\hline Liver & $22.2^{\mathrm{c}}$ \\
\hline Lung & $19.0^{\mathrm{c}}$ \\
\hline $\mathrm{CNS}$ & $5.2^{\mathrm{c}}$ \\
\hline Other & $33.3^{\mathrm{c}}$ \\
\hline More than one & $47.2^{\mathrm{c}}$ \\
\hline \multicolumn{2}{|l|}{ Pain category } \\
\hline Somatic pain & $56.9^{\mathrm{c}}$ \\
\hline Mixed pain & $27.8^{\mathrm{c}}$ \\
\hline Visceral pain & $11.6^{\mathrm{c}}$ \\
\hline Neuropathic pain & $3.6^{\mathrm{c}}$ \\
\hline
\end{tabular}

${ }^{\mathrm{a}}$ Number

${ }^{\mathrm{b}}$ Median (minimum to maximum)

${ }^{\mathrm{c}}$ Percentage (\%) oxycodone, 174-245 $\mathrm{nM}$ for noroxycodone, 2.3-3.0 nM for oxymorphone and $26-34 \mathrm{nM}$ for noroxymorphone.

The noroxycodone/oxycodone and oxymorphone/oxycodone ratios varied from 0.1 to 24.4 (median 1.1) and from 0.00032 to 0.21 (median 0.02 ) respectively (Table 3 ). The $95 \% \mathrm{CI}$ for the mean was $1.4-1.8 \mathrm{nM}$ and 0.020 $0.025 \mathrm{nM}$ respectively. The distributions of these ratios are shown in Fig. 3 as a histogram and P-P plots. Four patients lacked a noroxycodone/oxycodone ratio, because there was no detectable oxycodone and noroxycodone $(n=2)$, no detectable oxycodone $(n=1)$ and no detectable noroxycodone $(n=1)$. Fifteen patients had an oxymorphone/oxycodone ratio of zero, 12 because oxymorphone was not detected, and 3 because oxycodone was not found. These patients were given a fictive low serum concentration value (assay detection limit $\times 0.5$ ) and were included in the distribution (Fig. 3).

\section{Relations between serum concentrations and ratios and the patient-related variables}

Serum concentrations of oxycodone $\left(\mathrm{r}_{\mathrm{s}}=0.71\right)$, oxymorphone $\left(r_{s}=0.56\right)$, noroxycodone $\left(r_{s}=0.75\right)$ and noroxymorphone $\left(\mathrm{r}_{\mathrm{s}}=0.68\right)$ correlated $(p<0.001$ for all $)$ with oxycodone total daily dosage (Fig. 4, shown only for oxycodone). Serum concentrations of noroxycodone $\left(\mathrm{r}_{\mathrm{s}}\right.$, females $=0.79, \mathrm{r}_{\mathrm{s} \text {, males }}=$ 0.76 ), oxymorphone $\left(\mathrm{r}_{\mathrm{s}}\right.$, females $\left.=0.73, \mathrm{r}_{\mathrm{s} \text {, males }}=0.66\right)$ and noroxymorphone (rs, females $=0.64$, rs, males $=0.59$ ) were closely associated $(p<0.001$ for all) with oxycodone serum concentrations for both men and women. At a given level of oxycodone, women have higher corresponding metabolite serum concentrations (Fig. 5). Correlations between oxycodone daily dose and the ratios oxymorphone/oxycodone ( $\mathrm{rs}$, females $=-0.32$, rs, males $=-0.33$ ) and noroxycodone $/$ oxycodone (rs, females $=-0.33$, rs, males $=-0.13$ ) were low $(p<0.001$ for all; data not shown). Moreover, there was no correlation between serum concentration and GFR (data not shown).

Table 4 shows the results from the multiple linear regression analysis with the outcomes oxycodone serum concentrations, the oxymorphone/oxycodone ratio and the noroxycodone/oxycodone ratio, respectively.

"Oxycodone total daily dose", "time from last oxycodone dose (scheduled or rescue) to blood sample" ( $p \leq$ 0.001 for both), "CYP3A4 inducer" ( $p=0.001)$, "CYP3A4 inhibitor $(p=0.044)$ and sex $(p=0.010)$ were associated with oxycodone serum concentrations. Together these factors explain $35 \%\left(\mathrm{R}^{2}=0.35\right)$ of the observed variation. Total daily dose had the largest standardised coefficient, and was therefore the most prominent of all variables. Total daily dose and use of CYP3A4 inhibitors displayed positive association. This means that increasing the dose and 
Table 2 Oxycodone scheduled daily dose, total daily dose of oxycodone rescue medication and total daily oxycodone (scheduled and rescue; mg/ $24 \mathrm{~h}$ ) given as median, 25 th and 75 th percentile, minimum to maximum values, mean and $95 \% \mathrm{CI}$ for the hospitalised patients

\begin{tabular}{|c|c|c|c|c|c|c|c|}
\hline \multirow[t]{2}{*}{ Oxycodone daily dose: } & \multirow[t]{2}{*}{ Median } & \multirow[t]{2}{*}{25 th percentile } & \multirow[t]{2}{*}{ 75th percentile } & \multirow[t]{2}{*}{ Minimum to maximum } & \multirow[t]{2}{*}{ Mean } & \multicolumn{2}{|c|}{$95 \% \mathrm{CI}$} \\
\hline & & & & & & Low & High \\
\hline Scheduled & 60 & 40 & 120 & $10-760$ & 98 & 87 & 109 \\
\hline Rescue & 20 & 10 & 40 & $5-360$ & 35 & 29 & 42 \\
\hline Total (scheduled and rescue) & 80 & 40 & 125 & $10-960$ & 115 & 102 & 128 \\
\hline
\end{tabular}

inhibition of the CYP3A4 metabolic pathway favour increased oxycodone serum concentrations. Men were predicted to have about $30 \%$ higher oxycodone serum concentrations than women. "CYP3A4 inducer" and "time from last oxycodone dose (scheduled or rescue) to blood sample" displayed negative associations. Thus, longer time between tablet intake and blood sampling and use of a CYP3A4 inducer as concomitant medication decrease oxycodone serum concentrations. Users of CYP3A4 inducer drugs are predicted to have $84 \%$ (see notes to Table 4 for calculation) lower serum concentrations of oxycodone than those without the CYP3A4 inducer drug. Users of CYP3A4 inhibitors are predicted to have $60 \%$ higher oxycodone serum concentrations than non-users.

The variables "oxycodone total daily dose" $(p=0.004)$, "number of medications except opioids taken in the last $24 \mathrm{~h}(p=0.003)$ and "CYP3A4 inducer" $(p=0.010)$, only explained $5 \%\left(\mathrm{R}^{2}=0.05\right)$ of the observed variation in oxymorphone/oxycodone ratio. The variables total daily dose and number of medications were negatively associated with this ratio. Thus, an increase in total daily dose or "number of medications" decreases the oxymorphone/oxy- codone ratio. Users of CYP3A4 inducers are predicted to have a three times higher oxymorphone/oxycodone ratio, than non-CYP3A4 users. All variables had a similar impact on the explained variation (see their standardised coefficients, Table 4).

Except for age, Karnofsky performance status, "time since starting opioids" and "number of medications", the ratio noroxycodone/oxycodone was associated with all examined variables, with oxycodone total daily dose being the most important. However, these variables together only explained $19 \%\left(\mathrm{R}^{2}=0.19\right)$ of the variation. Use of CYP3A4 inhibitor $(p=0.000)$, BMI $(p=0.019)$ and glomerular filtration rate $(p=0.002)$ showed a negative association. Men are predicted to have $22 \%$ (see notes to Table 4 for calculation) lower noroxycodone/oxycodone ratio than women $(p=$ 0.002), and use of a CYP3A4 inhibitor is predicted to give a $49 \%$ reduction in ratio compared with non-users of CYP3A4 inhibitors. An increase in BMI or glomerular filtration rate will decrease the ratio. Users of CYP3A4 inducers are predicted to have about 4 times higher noroxycodone/oxycodone ratio. Users of systemic steroids are predicted to have $15 \%$ lower ratio than those not using
Table 3 Uncorrected serum concentrations (nM) of oxycodone, noroxycodone, oxymorphone, noroxymorphone and dose-corrected $\left(\mathrm{nM} \times 100 \mathrm{mg} 24 \mathrm{~h}^{-1} /\right.$ dose $\left.24 \mathrm{~h}^{-1}\right)$ serum concentrations, and ratios noroxycodone/oxycodone and oxymorphone/oxycodone given as median, 25th and 75th percentiles, minimum to maximum values, mean and $95 \%$ CI for mean for the hospitalised patients

\begin{tabular}{|c|c|c|c|c|c|c|c|}
\hline \multirow[t]{2}{*}{ Serum concentrations } & \multirow[t]{2}{*}{ Median } & \multirow[t]{2}{*}{25 th percentile } & \multirow[t]{2}{*}{ 75th percentile } & \multirow[t]{2}{*}{ Minimum to maximum } & \multirow[t]{2}{*}{ Mean } & \multicolumn{2}{|c|}{$95 \% \mathrm{CI}$} \\
\hline & & & & & & Low & High \\
\hline Oxycodone $^{\mathrm{a}}$ & 97 & 43 & 201 & $0-1,890$ & 161 & 139 & 183 \\
\hline Oxycodone $^{\mathrm{b}}$ & 144 & 90 & 225 & $0-1,294$ & 186 & 170 & 203 \\
\hline Noroxycodone $^{\mathrm{a}}$ & 101 & 44 & 211 & $0-3,571$ & 209 & 174 & 245 \\
\hline Noroxycodone $^{\mathrm{b}}$ & 161 & 103 & 261 & $0-3,032$ & 212 & 188 & 235 \\
\hline Oxymorphone $^{\mathrm{a}}$ & 1.5 & 0.7 & 3.2 & $0-25$ & 2.6 & 2.3 & 3.0 \\
\hline Oxymorphone $^{\mathrm{b}}$ & 2.2 & 1.2 & 4.2 & $0-34$ & 3.4 & 3.0 & 3.8 \\
\hline Noroxymorphone $^{\mathrm{a}}$ & 17 & 8 & 39 & $0-509$ & 30 & 26 & 34 \\
\hline Noroxymorphone $^{\mathrm{b}}$ & 29 & 18 & 44 & $0-360$ & 34 & 31 & 38 \\
\hline Ratio noroxycodone/oxycodone ${ }^{\mathrm{a}}$ & 1.1 & 0.7 & 1.9 & $0.1-24.4$ & 1.6 & 1.4 & 1.8 \\
\hline Ratio oxymorphone/oxycodone $\mathrm{e}^{\mathrm{a}}$ & 0.02 & 0.01 & 0.03 & $0.00032-0.21$ & 0.02 & 0.02 & 0.02 \\
\hline
\end{tabular}

${ }^{a}$ Uncorrected serum concentrations

${ }^{\mathrm{b}}$ Dose-corrected serum concentrations 

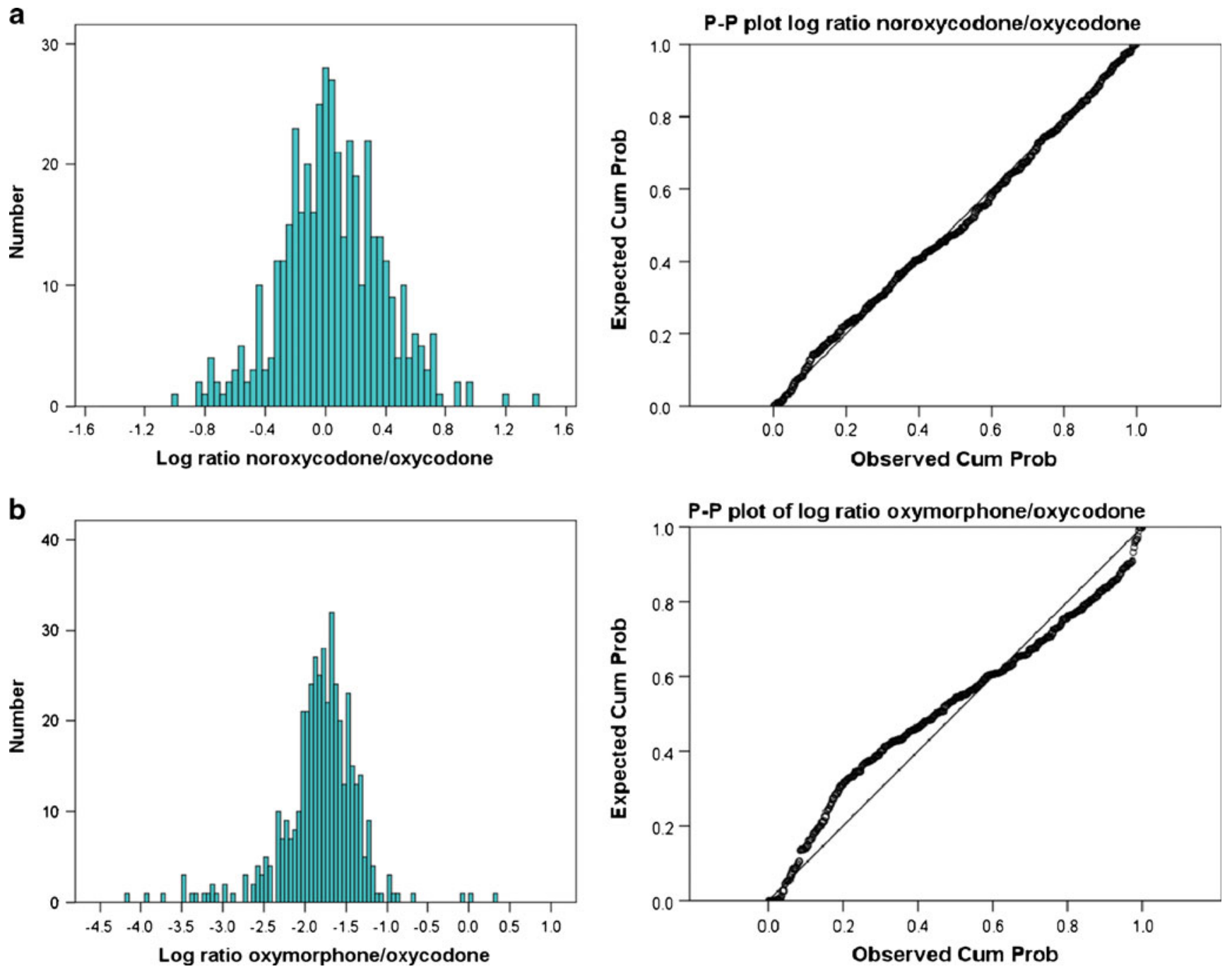

Fig. 3 a $\log _{10}$-transformed distributions of CYP3A4-dependent noroxycodone/oxycodone ratio and b the CYP2D6-dependent oxymorphone/oxycodone ratio. Histograms on the left and P-P

plots (expected cumulative probability vs observed cumulative probability) on the right

steroids. The remaining variables predict increased noroxycodone/oxycodone ratio.

Forty-seven of the 439 patients used immediate-release oxycodone every 4-6 h, while the remaining 392 were using controlled-release oxycodone approximately every $12 \mathrm{~h}$. All the regression analyses were also performed without the immediate release users to determine whether oxycodone formulation affected the data. The outcome of this analysis did not differ from the outcome of the complete analysis. Serum concentrations of oxycodone $(p=0.49)$, oxymorphone $(p=0.12)$ and the ratio oxymorphone/oxycodone $(p=0.15)$ did not differ between users and non-users of CYP2D6 inhibitors.

The following variables included in the analyses did not explain variability in any of the outcomes: age, Karnofsky performance status and "time since starting opioids".

Finally, other variables that were explored, but not included in the multiple regression analyses were; "use of steroids", "use of dexamethasone", "use of CYP2D6 inhibitor", "having liver metastases" and "time since starting opioids in months".

\section{Discussion}

The focus of this study was to examine if common clinically observed factors could predict variation in oxycodone serum concentrations and the metabolite to oxycodone ratios in cancer patients. It was shown that oxycodone total daily dose, use of CYP3A4 inducers/ inhibitors, sex and the time from the last oxycodone dose to blood sample explained variations in serum concentrations 


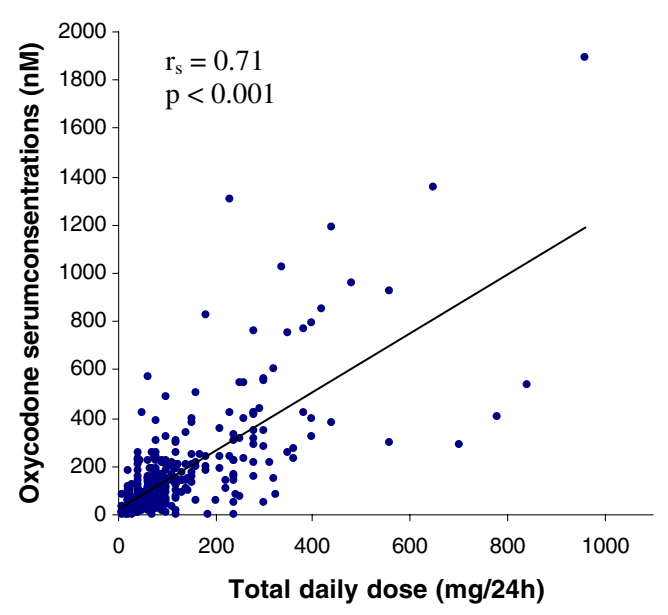

Fig. 4 Spearman rank correlation $\left(r_{s}\right)$ between oxycodone total daily dose $\left(\mathrm{mg} / 24^{-1}\right)$ and serum concentrations of oxycodone $\left(\mathrm{nM} ; \mathrm{r}_{\mathrm{s}}=0.71\right.$, $p<0.001)$ for the hospitalised patients

of oxycodone. It was also observed that the ratios for the serum concentrations of the metabolites noroxycodone and oxymorphone to oxycodone were influenced by the use of CYP3A4 inducer drugs and oxycodone total daily dose. The number of medications except opioids taken in the last $24 \mathrm{~h}$ was the only additional factor for the oxymorphone/ oxycodone ratio. The noroxycodone/oxycodone ratio was in addition influenced by sex, use of CYP3A4 inhibitor, BMI, GFR, albumin and time from last dose to blood sample. However, the regression models could only explain minor parts of the variability of serum concentration and ratios of oxycodone and metabolites.

The wide concentration ranges of oxycodone and metabolite serum concentrations observed were expected, not least due to the wide dose range observed in this sample. These observations agree with the studies that showed large individual differences in serum concentrations even after dose correction for patients receiving morphine $[4,51-53]$. Total daily dose correlated highly with the variable that best explained the variability of oxycodone serum concentrations. Rescue medication is frequently used by cancer pain patients. In this sample $44 \%$ of the patients used rescue medication, the majority oxycodone $(90 \%)$. The use of rescue medication may confound data interpretation; however, this was corrected for by using the two variables "time since last dose" and "total daily dose" in the regression analyses.

The observed sex differences related to dose and serum concentrations of oxycodone are interesting. First, men used higher total daily doses than women (median $80 \mathrm{mg} /$ $24 \mathrm{~h}$ vs $70 \mathrm{mg} / 24 \mathrm{~h}, p=0.03$ ). It is unlikely that the higher body weight of men accounts for this difference as dosing for cancer pain is not based on weight, but titration to the desired effect. It is more likely that it reflects that men may be less sensitive than women to opioids, and therefore may require higher doses to relieve similar levels of pain $[54,55]$. There are no published data on sex differences in oxycodone dosage requirements, although studies with morphine have shown that men need at least $30-40 \%$ more morphine than women for pain relief [54]. This agrees with the finding in this study where men had higher serum concentrations of oxycodone than women (about 30\%, as calculated from the regression analysis). Since sex and daily dose are independent variables in the analyses, sex as a factor in itself also contributes to the difference in oxycodone serum concentration. This may well be explained by a higher metabolic capacity in women as discussed below.

Formation of noroxycodone by CYP3A4 is the major elimination pathway of oxycodone [35]. The observation that men are predicted to have a $31 \%$ lower noroxycodone/ oxycodone ratio than women may fit with higher CYP3A4 activity in women. Thus, the higher oxycodone serum concentrations in men may be explained by a lower activity of CYP3A4 compared with women. This is supported by a number of in vitro studies [56-59]. Also, in vivo studies have shown that women seem to exhibit faster clearance of CYP3A4-metabolising drugs [22, 23, 60], although some studies have failed to detect this clearance difference $[61,62]$.

A secondary outcome was to assess whether clinical variables can be used to predict the metabolite to parent drug ratios, assuming that this exploration of ratios could shed light on the elimination pathways of oxycodone. It was unexpected that oxycodone total daily dose explained the variability of metabolite to parent drug ratios. We would expect both ratios to remain constant for an individual, assuming that the elimination pathways of oxycodone followed first-order kinetics. Thus, this finding may indicate that all processes involved in these ratios might not obey first-order kinetics.

Oxymorphone is formed from oxycodone mainly by CYP2D6 enzymes and excreted mainly as an oxymorphone3-glucuronide conjugate [31]. CYP2D6 is under polymorphic regulation. The oxymorphone/oxycodone ratio may therefore be subject to a polymodal distribution. While the distribution of the noroxycodone/oxycodone ratio was normal as expected for a potential phenotypic expression of CYP3A4, this was not obvious for the oxymorphone/ oxycodone ratio. Both histogram and P-P plot showed indices of multimodal distribution, although no clear bimodality could be seen. One reason for this may be that oxymorphone is further metabolised by UDP-glucuronosyltransferase to oxymorphone-3-glucuronide and variability in this metabolic pathway may influence the distribution of the oxymorphone/oxycodone ratio. Also, factors other than genotype may explain the variability of this ratio as discussed below. 

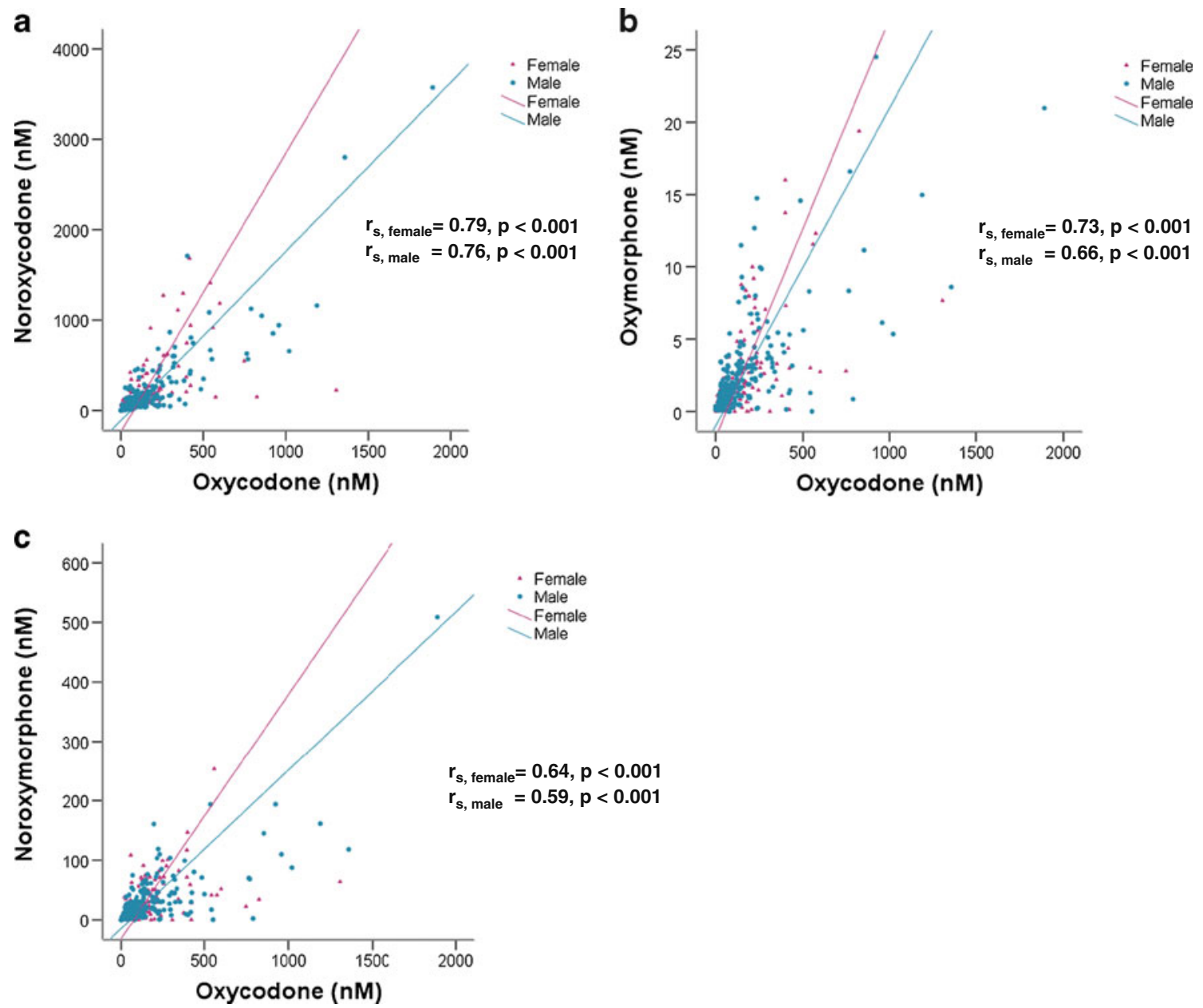

Fig. 5 a-c Spearman rank correlations $\left(r_{s}\right)$ for men $\left(r_{s, \text { males }}\right)$ and women $\left(r_{s}\right.$, females $)$ between oxycodone and noroxycodone, oxymorphone and noroxymorphone serum concentrations $\left(\mathrm{r}_{\mathrm{s}}=0.59-0.79, p<0.001\right)$ for the hospitalised patients

CYP2D6 is subject to significant inhibition of its activity by a number of other drugs $[18,31]$. Most of the coadministered drugs used in our study are not known to inhibit CYP2D6, as only $8 \%$ of the patients $(n=35)$ were treated with known CYP2D6 inhibitors. Use of CYP2D6 inhibitors did not influence the oxymorphone/oxycodone ratio. Moreover, the low number of known CYP2D6 inhibitors observed in this large sample of patients recruited from several centres indicates that the use of these drugs is infrequently indicated in cancer pain patients. However, it remains the case that increasing numbers of co-administered drugs reduce the ratio $\mathrm{pf}$ oxymorphone to oxycodone.

Many factors seem to influence the noroxycodone/ oxycodone ratio. Some of the factors, such as sex, GFR, use of CYP3A4 inducers/inhibitors and "time from last oxycodone (scheduled or rescue) dose to blood sample" can probably be explained by common pharmacokinetic knowledge. GFR is an independent variable predicting a noroxycodone/oxycodone ratio rise when GFR decreases.
This rise may possibly be explained by reduced renal clearance, causing a relative accumulation of noroxycodone, which is mainly excreted through the kidneys. In fact, the AUC ratio for noroxycodone/oxycodone was three times higher in renal failure patients compared with subjects with normal renal function after intravenous administration of oxycodone [37]. Thus, reduced renal function may change several aspects of the overall pharmacokinetics of oxycodone.

Two of the factors that influence the noroxycodone/ oxycodone ratio, BMI and albumin, are difficult to explain. Serum concentrations of oxycodone have previously shown to be associated with albumin [63]. This could potentially have explained the ratio, although albumin did not contribute to the variability of oxycodone serum concentrations itself.

The overall median noroxycodone/oxycodone ratios in this study in cancer patients was in accordance with results from previous studies [9, 35, 39]. The oxymorphone/ oxycodone ratio was also in line with other studies, and 
Table 4 Multiple linear regression models with factors predicting the serum concentrations of oxycodone and the ratios oxymorphone/oxycodone and noroxycodone/oxycodone

\begin{tabular}{|c|c|c|c|c|c|c|}
\hline \multirow[t]{2}{*}{ Factors $^{\mathrm{a}}$ associated with } & \multicolumn{2}{|c|}{ Unstandardised coefficients $^{\mathrm{b}}$} & \multirow{2}{*}{$\begin{array}{l}\text { Standardised } \\
\text { coefficients }\end{array}$} & \multirow[b]{2}{*}{ Significance } & \multicolumn{2}{|c|}{$\begin{array}{l}95 \% \text { confidence interval } \\
\text { for } \mathrm{B}\end{array}$} \\
\hline & $\mathrm{B}$ & $\begin{array}{l}\text { Standard } \\
\text { error }\end{array}$ & & & $\begin{array}{l}\text { Lower } \\
\text { bound }\end{array}$ & $\begin{array}{l}\text { Upper } \\
\text { bound }\end{array}$ \\
\hline \multicolumn{7}{|l|}{ Oxycodone $\left(n=433 ; \mathrm{R}^{2}=0.35\right)^{\mathrm{b}}$} \\
\hline Oxycodone total daily dose & 0.002 & 0.0002 & 0.491 & 0.000 & 0.002 & 0.002 \\
\hline CYP3A4 inducer ${ }^{\mathrm{c}}$ & -0.786 & 0.233 & -0.131 & 0.001 & -1.242 & -0.327 \\
\hline CYP3A4 inhibitor ${ }^{\mathrm{c}}$ & 0.204 & 0.101 & 0.078 & 0.044 & 0.005 & 0.403 \\
\hline $\operatorname{Sex}^{\mathrm{d}}$ & 0.113 & 0.045 & 0.098 & 0.012 & 0.025 & 0.201 \\
\hline Time from last oxycodone dose to blood sample & -0.027 & 0.006 & -0.189 & 0.000 & -0.038 & -0.016 \\
\hline \multicolumn{7}{|l|}{ Ratio oxymorphone/oxycodone $\left(n=438 ; \mathrm{R}^{2}=0.05\right)^{\mathrm{b}}$} \\
\hline Oxycodone total daily dose & -0.0004 & 0.0001 & -0.136 & 0.004 & -0.0007 & -0.0001 \\
\hline CYP3A4 inducer ${ }^{\mathrm{c}}$ & 0.607 & 0.234 & 0.122 & 0.010 & 0.147 & 1.067 \\
\hline $\begin{array}{l}\text { Number of medications (excluding opioids) taken } \\
\text { in the last } 24 \mathrm{~h}\end{array}$ & -0.024 & 0.008 & -0.140 & 0.003 & -0.039 & -0.008 \\
\hline \multicolumn{7}{|l|}{ Ratio noroxycodone/oxycodone $\left(n=396 ; \mathrm{R}^{2}=0.19\right)^{\mathrm{b}}$} \\
\hline Oxycodone total daily dose & 0.001 & 0.0001 & 0.231 & 0.000 & 0.0003 & 0.001 \\
\hline Time from last oxycodone dose to blood sample & 0.012 & 0.004 & 0.147 & 0.002 & 0.004 & 0.020 \\
\hline Albumin & 0.006 & 0.002 & 0.132 & 0.005 & 0.002 & 0.010 \\
\hline $\operatorname{Sex}^{\mathrm{d}}$ & -0.110 & 0.033 & -0.160 & 0.001 & -0.175 & -0.045 \\
\hline CYP3A4 inducer ${ }^{\mathrm{c}}$ & 0.602 & 0.183 & 0.153 & 0.001 & 0.242 & 0.962 \\
\hline CYP3A4 inhibitor ${ }^{\mathrm{c}}$ & -0.294 & 0.068 & -0.197 & 0.000 & -0.427 & -0.160 \\
\hline Systemic steroids ${ }^{\mathrm{c}, \mathrm{e}}$ & -0.070 & 0.032 & -0.102 & 0.028 & -0.132 & -0.008 \\
\hline BMI & -0.009 & 0.004 & -0.109 & 0.019 & -0.017 & -0.001 \\
\hline Glomerular filtration rate & -0.001 & 0.0004 & -0.161 & 0.001 & -0.002 & -0.0005 \\
\hline
\end{tabular}

${ }^{\mathrm{a}}$ Independent variables in all analyses were age (years), sex, BMI $\left(\mathrm{kgm}^{-2}\right)$, Karnofsky performance status (\%), time from last oxycodone dose to sample (h), oxycodone total daily dose ( $\mathrm{mg} / 24 \mathrm{~h}$ ), time since starting opioids (months), number of concomitant medications in the last $24 \mathrm{~h}$, use of CYP3A4 inhibitor (yes/no), use of CYP3A4 inducer (yes/no), glomerular filtration rate $\left(\mathrm{mlmin}^{-1} 1.73 \mathrm{~m}^{-2}\right)$ and albumin $\left(\mathrm{gl} 1^{-1}\right) \mathrm{serum}$ concentrations

${ }^{\mathrm{b}}$ Coefficients are in $\log 10$ form (e.g. $10^{0.002 \times \text { oxycodone daily dose }}$ )

${ }^{\mathrm{c}}$ Yes $=1$, no $=0$ (user of systemic steroids yes: $10^{-0.070 \times 1}$, NO: $10^{-0.070 \times 0}$ )

${ }^{\mathrm{d}} \mathrm{Men}=1$, women $=0$ (male oxycodone serum concentration: $10^{0.113 \times 1}$, women: $10^{0.113 \times 0}$, noroxycodone/oxycodone ratio men: $10^{-0.110 \times 1}$, women: $10^{-0.110 \times 0}$ )

${ }^{\mathrm{e}}$ The patients in the CYP3A4 inducer $(n=4)$ group also used systemic steroids

confirms the minor amount of this active metabolite compared with its parent substance in this group. A previous study has claimed that the levels of oxymorphone in the brain relative to the parent drug oxycodone [35] is very low. However, recent experimental studies in humans have documented that oxymorphone contributes to analgesia $[64,65]$. Although not shown, this may therefore also be the case in cancer patients.

Concomitant medication with CYP3A4 inhibitors, as expected, reduced the CYP3A4-mediated noroxycodone/ oxycodone ratio. The use of CYP3A4 inducers on the other hand, influenced all three examined outcomes. The observed changes in the ratios comply with an increased
CYP3A4 activity, thus lowering oxycodone concentration and increasing those of noroxycodone. However, except for systemic steroids, CYP3A4 inducers were used by only 4 patients and these 4 alone had a remarkable influence on both ratios and the oxycodone serum concentrations. Thus, potential CYP3A4 drug-drug interactions, especially with the use of CYP3A4 inducers, are also important to consider when administering oxycodone in cancer patients.

We recognise that compared with experimental pharmacokinetic studies in volunteers (healthy or with cancer) this study is subject to a number of confounding factors. However, this multicentre cross-sectional study resulted in a patient population representative of the heterogeneity of cancer patients 
physicians are faced with in day-to-day clinical work. Moreover, this study is unique with its large sample size where clinical characteristics and extensive data on the serum concentrations of oxycodone and its major metabolites are combined. The use of multiple regression analysis made it possible to control for differences between the patients with respect to common clinical variables. Thus, despite the heterogeneity of the sample, a number of plausible variables related to the variability of the outcomes were also confirmed in cancer patients. The explained variability of the dependent variables was low in these regression analyses, especially for the ratios, which comply with those of a previous publication [4]. Plausible reasons for this are the fact that cancer patients are a very heterogeneous group of patients; the origin and progression of their cancer differ, their metastatic status differs, their metabolic status differs, and of course there are genetic and perception differences.

\section{Conclusions}

Sex differences related to opioids and metabolism may also be true in a cancer population. Drug-drug interactions related to CYP2D6 are probably of little clinical significance; however, use of CYP3A4 inducers or inhibitors should be carefully monitored, as these might significantly influence the serum concentrations, which may possibly change the effects of oxycodone. Pharmacokinetics in special populations, such as patients with renal failure and obesity, should be studied further. Finally, the variables, including daily dose, explained one third of the variability of oxycodone serum concentrations and only minor parts of the variability of the ratios in this population.

\begin{abstract}
Acknowledgements We would like to thank the European Association for Palliative Care Research Network (EAPC-RN) for contributing to the organisation of the European Pharmacogenetic Opioid Study (EPOS). We also want to acknowledge the contribution of all investigators and each participating research centre: Andrew Davies, Sutton/Chelsea, UK; Augusto Caraceni, Alessandra Pigni, Milan, Italy; Danilo Miotti, Pavia, Italy; Eeva Salminen, Turku, Finland; Eriphili Argyra, Athens, Greece; Florian Strasser, St. Gallen Switzerland; Irena Poviloniene, Vilnius, Lithuania; Jon Håvard Loge, Oslo, Norway; Kristin Bjordal, Oslo, Norway; Lucas Radbruch, Aachen, Germany; Marianne Kloke, Essen, Germany; Marco Maltoni, Forli, Italy; Per Sjøgren, Copenhagen, Denmark; Rainer Sabatowski, Dresden, Germany; Staffan Lundström, Stockholm, Sweden; Stein Kaasa, Trondheim, Norway; and Valgerdur Sigurdardottir, Reykjavik, Iceland.

We thank Gunnhild Jakobsen for organising the data collection and Peter Fayers for advice on the statistical methods in this paper. This work was supported by grants from the Norwegian Research Council, the Norwegian Cancer Society and the EU 6th framework.
\end{abstract}

Open Access This article is distributed under the terms of the Creative Commons Attribution Noncommercial License which permits any noncommercial use, distribution, and reproduction in any medium, provided the original author(s) and source are credited.

\section{References}

1. Wilson KG, Max CH, Allard P, Chary S, Gagnon PR, Macmillan K, De LM, O'Shea F, Kuhl D, Fainsinger RL (2009) Prevalence and correlates of pain in the Canadian National Palliative Care Survey. Pain Res Manag 14(5):365-370

2. Holtan A, Aass N, Nordoy T, Haugen DF, Kaasa S, Mohr W, Kongsgaard UE (2007) Prevalence of pain in hospitalised cancer patients in Norway: a national survey. Palliat Med 21(1):7-13

3. Van den Beuken-van Everdingen MH, de Rijke JM, Kessels AG, Schouten HC, van Kleef M, Patijn J (2007) Prevalence of pain in patients with cancer: a systematic review of the past 40 years. Ann Oncol 18(9):1437-1449

4. Klepstad P, Dale O, Kaasa S, Zahlsen K, Aamo T, Fayers P, Borchgrevink PC (2003) Influences on serum concentrations of morphine, M6G and M3G during routine clinical drug monitoring: a prospective survey in 300 adult cancer patients. Acta Anaesthesiol Scand 47(6):725-731

5. McQuay HJ, Carroll D, Faura CC, Gavaghan DJ, Hand CW, Moore RA (1990) Oral morphine in cancer pain: influences on morphine and metabolite concentration. Clin Pharmacol Ther 48(3):236-244

6. Bruera E, Belzile M, Pituskin E, Fainsinger R, Darke A, Harsanyi Z, Babul N, Ford I (1998) Randomized, double-blind, cross-over trial comparing safety and efficacy of oral controlled-release oxycodone with controlled-release morphine in patients with cancer pain. J Clin Oncol 16(10):3222-3229

7. American Pain Society (1999) Principles of analgesic use in the treatment of acute pain and cancer pain, 4th edn. American Pain Society, Glenview, IL

8. Leow KP, Smith MT, Williams B, Cramond T (1992) Single-dose and steady-state pharmacokinetics and pharmacodynamics of oxycodone in patients with cancer. Clin Pharmacol Ther 52(5):487-495

9. Poyhia R, Seppala T, Olkkola KT, Kalso E (1992) The pharmacokinetics and metabolism of oxycodone after intramuscular and oral administration to healthy subjects. Br J Clin Pharmacol 33(6):617-621

10. Gourlay GK, Cherry DA, Cousins MJ (1986) A comparative study of the efficacy and pharmacokinetics of oral methadone and morphine in the treatment of severe pain in patients with cancer. Pain 25(3):297-312

11. Sawe J (1986) High-dose morphine and methadone in cancer patients. Clinical pharmacokinetic considerations of oral treatment. Clin Pharmacokinet 11(2):87-106

12. Hoskin PJ, Hanks GW, Aherne GW, Chapman D, Littleton P, Filshie J (1989) The bioavailability and pharmacokinetics of morphine after intravenous, oral and buccal administration in healthy volunteers. Br J Clin Pharmacol 27(4):499-505

13. Kaiko RF, Benziger DP, Fitzmartin RD, Burke BE, Reder RF, Goldenheim PD (1996) Pharmacokinetic-pharmacodynamic relationships of controlled-release oxycodone. Clin Pharmacol Ther 59(1):52-61

14. Jannetto PJ, Bratanow NC (2009) Utilization of pharmacogenomics and therapeutic drug monitoring for opioid pain management. Pharmacogenomics 10(7):1157-1167

15. Citron ML, Kaplan R, Parris WC, Croghan MK, Herbst LH, Rosenbluth RJ, Reder RF, Slagle NS, Buckley BJ, Kaiko RF (1998) Long-term administration of controlled-release oxycodone tablets for the treatment of cancer pain. Cancer Invest 16(8):562571

16. Mucci-LoRusso P, Berman BS, Silberstein PT, Citron ML, Bressler L, Weinstein SM, Kaiko RF, Buckley BJ, Reder RF (1998) Controlled-release oxycodone compared with controlledrelease morphine in the treatment of cancer pain: a randomized, double-blind, parallel-group study. Eur J Pain 2(3):239-249 
17. Moore KA, Ramcharitar V, Levine B, Fowler D (2003) Tentative identification of novel oxycodone metabolites in human urine. $\mathrm{J}$ Anal Toxicol 27(6):346-352

18. Wilkinson GR (2005) Drug metabolism and variability among patients in drug response. N Engl J Med 352(21):2211-2221

19. Guengerich FP (2005) Human cytochrome P450 enzymes. In: Ortiz de Montellano PR (ed) Cytochrome P450: structure, mechanism, and biochemistry, 3 edn. Kluwer Academic/Plenum, New York, p 424

20. Armstrong SC, Wynn GH, Sandson NB (2009) Pharmacokinetic drug interactions of synthetic opiate analgesics. Psychosomatics 50(2):169-176

21. Mertz D, Battegay M, Marzolini C, Mayr M (2009) Drug-drug interaction in a kidney transplant recipient receiving HIV salvage therapy and tacrolimus. Am J Kidney Dis 54(1):E1-E4

22. Harris RZ, Benet LZ, Schwartz JB (1995) Gender effects in pharmacokinetics and pharmacodynamics. Drugs 50(2):222-239

23. Cotreau MM, von Moltke LL, Greenblatt DJ (2005) The influence of age and sex on the clearance of cytochrome P450 3A substrates. Clin Pharmacokinet 44(1):33-60

24. Dorne JL, Walton K, Renwick AG (2003) Human variability in CYP3A4 metabolism and CYP3A4-related uncertainty factors for risk assessment. Food Chem Toxicol 41(2):201-224

25. El Mouelhi M, Didolkar MS, Elias EG, Guengerich FP, Kauffman FC (1987) Hepatic drug-metabolizing enzymes in primary and secondary tumors of human liver. Cancer Res 47(2):460-466

26. Yang LQ, Li SJ, Cao YF, Man XB, Yu WF, Wang HY, Wu MC (2003) Different alterations of cytochrome P450 3A4 isoform and its gene expression in livers of patients with chronic liver diseases. World J Gastroenterol 9(2):359-363

27. Kirchheiner J (2008) CYP2D6 phenotype prediction from genotype: which system is the best? Clin Pharmacol Ther 83(2):225-227

28. Zanger UM, Raimundo S, Eichelbaum M (2004) Cytochrome P450 2D6: overview and update on pharmacology, genetics, biochemistry. Naunyn Schmiedebergs Arch Pharmacol 369(1):23-37

29. Richelson E (1997) Pharmacokinetic drug interactions of new antidepressants: a review of the effects on the metabolism of other drugs. Mayo Clin Proc 72(9):835-847

30. Bertz RJ, Granneman GR (1997) Use of in vitro and in vivo data to estimate the likelihood of metabolic pharmacokinetic interactions. Clin Pharmacokinet 32(3):210-258

31. Davis MP, Homsi J (2001) The importance of cytochrome P450 monooxygenase CYP2D6 in palliative medicine. Support Care Cancer 9(6):442-451

32. Brosen K, Gram LF, Haghfelt T, Bertilsson L (1987) Extensive metabolizers of debrisoquine become poor metabolizers during quinidine treatment. Pharmacol Toxicol 60(4):312-314

33. Ieiri I, Yamada S, Seto K, Morita T, Kaneda T, Mamiya K, Tashiro N, Higuchi S, Otsubo K (2003) A CYP2D6 phenotype-genotype mismatch in Japanese psychiatric patients. Pharmacopsychiatry 36 (5):192-196

34. Samer CF, Daali Y, Wagner M, Hopfgartner G, Eap CB, Rebsamen MC, Rossier MF, Hochstrasser D, Dayer P, Desmeules JA (2010) The effects of CYP2D6 and CYP3A activities on the pharmacokinetics of immediate release oxycodone. Br J Pharmacol 160(4):907-918

35. Lalovic B, Kharasch E, Hoffer C, Risler L, Liu-Chen LY, Shen DD (2006) Pharmacokinetics and pharmacodynamics of oral oxycodone in healthy human subjects: role of circulating active metabolites. Clin Pharmacol Ther 79(5):461-479

36. Kaiko RF (1997) Pharmacokinetics and pharmacodynamics of controlled-release opioids. Acta Anaesthesiol Scand 41(1 Pt 2): $166-174$

37. Kirvela M, Lindgren L, Seppala T, Olkkola KT (1996) The pharmacokinetics of oxycodone in uremic patients undergoing renal transplantation. J Clin Anesth 8(1):13-18
38. Tallgren M, Olkkola KT, Seppala T, Hockerstedt K, Lindgren L (1997) Pharmacokinetics and ventilatory effects of oxycodone before and after liver transplantation. Clin Pharmacol Ther 61 (6):655-661

39. Liukas A, Kuusniemi K, Aantaa R, Virolainen P, Neuvonen M, Neuvonen PJ, Olkkola KT (2008) Plasma concentrations of oral oxycodone are greatly increased in the elderly. Clin Pharmacol Ther 84(4):462-467

40. Hanley MJ, Abernethy DR, Greenblatt DJ (2010) Effect of obesity on the pharmacokinetics of drugs in humans. Clin Pharmacokinet 49(2):71-87

41. Linares CL, Decleves X, Oppert JM, Basdevant A, Clement K, Bardin C, Scherrmann JM, Lepine JP, Bergmann JF, Mouly S (2009) Pharmacology of morphine in obese patients: clinical implications. Clin Pharmacokinet 48(10):635-651

42. Karnofsky, David A, Abelmann, Walther H, Craver, Lloyd F, Burchenal, Joseph H (1948) The use of the nitrogen mustards in the palliative treatment of carcinoma. Cancer 1(4):634-656

43. Drug Interactions: Cytochrome P450 Drug Interaction Table, January 12, 2009. http://medicine.iupui.edu/clinpharm/ddis/table.asp Accessed 3 August 2010

44. Levey AS, Eckardt KU, Tsukamoto Y, Levin A, Coresh J, Rossert J, de Zeeuw D, Hostetter TH, Lameire N, Eknoyan G (2005) Definition and classification of chronic kidney disease: a position statement from Kidney Disease: Improving Global Outcomes (KDIGO). Kidney Int 67(6):2089-2100

45. Levey AS, Coresh J, Greene T, Marsh J, Kusek J, Van Lente Medicine F (2005) Estimating glomerular filtration rate with a new equation: MDRD4revised equation for use with IDMS-traceable serum creatinine. J Am Soc Nephrol 11[Suppl] :F-FC142

46. Green SB (1991) How many subjects does it take to do a regression analysis? Multivariate Behav Res 26(3):499-510

47. Miles J, Schevlin M (2001) Applying regression and correlation: a guide for students and researchers. Sage, Thousand Oaks, CA

48. Edwards SR, Smith MT (2007) Low-level quantitation of oxycodone and its oxidative metabolites, noroxycodone, and oxymorphone, in rat plasma by high-performance liquid chromatography-electrospray ionization-tandem mass spectrometry. J Chromatogr B Analyt Technol Biomed Life Sci 848(2):264-270

49. Dadgar D, Burnett PE, Choc MG, Gallicano K, Hooper JW (1995) Application issues in bioanalytical method validation, sample analysis and data reporting. J Pharm Biomed Anal 13 (2):89-97

50. Shah VP, Midha KK, Dighe S, McGilveray IJ, Skelly JP, Yacobi A, Layloff T, Viswanathan CT, Cook CE, McDowall RD (1991) Analytical methods validation: bioavailability, bioequivalence and pharmacokinetic studies. Conference report. Eur J Drug Metab Pharmacokinet 16(4):249-255

51. Faura CC, Collins SL, Moore RA, McQuay HJ (1998) Systematic review of factors affecting the ratios of morphine and its major metabolites. Pain 74(1):43-53

52. Hanna MH, D'Costa F, Peat SJ, Fung C, Venkat N, Zilkha TR, Davies S (1993) Morphine-6-glucuronide disposition in renal impairment. Br J Anaesth 70(5):511-514

53. Peterson GM, Randall CT, Paterson J (1990) Plasma levels of morphine and morphine glucuronides in the treatment of cancer pain: relationship to renal function and route of administration. Eur J Clin Pharmacol 38(2):121-124

54. Pleym H, Spigset O, Kharasch ED, Dale O (2003) Gender differences in drug effects: implications for anesthesiologists. Acta Anaesthesiol Scand 47(3):241-259

55. Sarton E, Olofsen E, Romberg R, Den HJ, Kest B, Nieuwenhuijs D, Burm A, Teppema L, Dahan A (2000) Sex differences in morphine analgesia: an experimental study in healthy volunteers. Anesthesiology 93(5):1245-1254 
56. Hunt CM, Westerkam WR, Stave GM (1992) Effect of age and gender on the activity of human hepatic CYP3A. Biochem Pharmacol 44(2):275-283

57. Schmidt R, Baumann F, Hanschmann H, Geissler F, Preiss R (2001) Gender difference in ifosfamide metabolism by human liver microsomes. Eur J Drug Metab Pharmacokinet 26(3):193-200

58. Wolbold R, Klein K, Burk O, Nussler AK, Neuhaus P, Eichelbaum M, Schwab M, Zanger UM (2003) Sex is a major determinant of CYP3A4 expression in human liver. Hepatology 38(4):978-988

59. Schirmer M, Rosenberger A, Klein K, Kulle B, Toliat MR, Nurnberg P, Zanger UM, Wojnowski L (2007) Sex-dependent genetic markers of CYP3A4 expression and activity in human liver microsomes. Pharmacogenomics 8(5):443-453

60. Chen M, Ma L, Drusano GL, Bertino JS Jr, Nafziger AN (2006) Sex differences in CYP3A activity using intravenous and oral midazolam. Clin Pharmacol Ther 80(5):531-538

61. George J, Byth K, Farrell GC (1995) Age but not gender selectively affects expression of individual cytochrome P450 proteins in human liver. Biochem Pharmacol 50(5):727-730
62. Williams ET, Leyk M, Wrighton SA, Davies PJ, Loose DS, Shipley GL, Strobel HW (2004) Estrogen regulation of the cytochrome P450 3A subfamily in humans. J Pharmacol Exp Ther 311(2):728-735

63. Leow KP, Wright AW, Cramond T, Smith MT (1993) Determination of the serum protein binding of oxycodone and morphine using ultrafiltration. Ther Drug Monit 15 (5):440-447

64. Samer CF, Daali Y, Wagner M, Hopfgartner G, Eap CB, Rebsamen MC, Rossier MF, Hochstrasser D, Dayer P, Desmeules JA (2010) Genetic polymorphisms and drug interactions modulating CYP2D6 and CYP3A activities have a major effect on oxycodone analgesic efficacy and safety. Br J Pharmacol 160 (4):919-930

65. Zwisler ST, Enggaard TP, Noehr-Jensen L, Pedersen RS, Mikkelsen S, Nielsen F, Brosen K, Sindrup SH (2009) The hypoalgesic effect of oxycodone in human experimental pain models in relation to the CYP2D6 oxidation polymorphism. Basic Clin Pharmacol Toxicol 104:335-344 